\title{
Arbor
}

\section{La investigación oncológica en España}

\section{Carlos López-Otín}

Arbor CLXVIII, 662 (Febrero 2001), 247-253 pp.

\section{Los cercanos orígenes de la investigación oncológica en España}

Mi trayectoria científica en el campo de la investigación oncológica es ciertamente reciente, pues se inició a principios de los años 90, cuando tras concluir una inolvidable etapa de aprendizaje en otros temas al amparo de Eladio Viñuela, decidí adentrarme en la exploración de los mecanismos de progresión tumoral. Tal vez por esta limitada experiencia personal, al aproximarme por primera vez al análisis de los orígenes y evolución de esta disciplina científica en nuestro país, acuciado por la redacción de este artículo, no he dejado de asombrarme.

En efecto, mi primera sorpresa ha sido constatar la escasa atención que tradicionalmente se ha prestado en nuestro país a la investigación oncológica. El Libro Blanco de la Oncología en España ${ }^{1}$ recoge algunos datos que pueden contribuir a avalar mi sorpresa por este desinterés histórico hacia la investigación sobre una enfermedad que causa la muerte de cerca de 100.000 españoles cada año ${ }^{2}$. Así, el primer Congreso de Investigación sobre el Cáncer en España no se celebró hasta 1982, cuando un grupo de pioneros se reunió en Madrid para reclamar la necesidad de una política científica estatal que facilitara el desarrollo de la investigación básica, aplicada y clínica acerca de esta enfermedad ${ }^{3}$. Hasta entonces, las distintas iniciativas en este sentido habían tenido un matiz eminentemente clínico y derivaron en buena medida del trabajo de investigadores agrupados en el denominado Instituto Nacional de Oncología, cuyo Departamento de Bioquímica Oncológica coordinado con el Consejo Superior de Investigaciones Científicas (CSIC) fue creado en 1963. Parece claro que las inquietudes de estos primeros investi- 
gadores oncológicos españoles no tuvieron una respuesta inmediata, pues las cifras que año tras año se siguieron dedicando a esta disciplina fueron realmente mínimas. Por ejemplo, en una fecha tan cercana como 1989, cuando la investigación oncológica mundial estaba en plena ebullición tras el descubrimiento de los oncogenes y los genes supresores de tumores, en España, y a través de la Comisión Interministerial de Ciencia y Tecnología (CICYT) sólo se financiaron 4 proyectos de investigación dentro del objetivo «Cáncer». Estos proyectos procedían de distintas Universidades y la cantidad total asignada a los mismos fue de 13 millones de pesetas, según los datos recogidos por Valladares y Alvarez ${ }^{1}$. De acuerdo con estos mismos autores, la participación del CSIC en la investigación sobre el cáncer en esta época tan reciente era meramente testimonial ya que «en los 147 proyectos de colaboración bilateral entre el CSIC y centros extranjeros, y los 112 proyectos de programas de la CE en las que interviene el CSIC, no existe la investigación oncológica» ${ }^{1}$. Parece, por tanto, que el problema de la limitada atención hacia esta disciplina no estaba únicamente en la tradicional escasez presupuestaria de la que ha venido adoleciendo la investigación científica en cualquier campo en nuestro país, sino también en la falta de un número significativo de grupos con una trayectoria consolidada en el terreno de la investigación oncológica. Durante esta época, la investigación clínica y epidemiológica sobre el cáncer recibió ayudas adicionales por parte del Fondo de Investigaciones Sanitarias de la Seguridad Social (FIS), que habitualmente financió un número muy amplio de proyectos de oncología (un total de 87, en el periodo 1988-89), pero con unas cantidades mínimas, ya que en muchos proyectos no se superaba el millón de pesetas, limitando seriamente la competitividad y alcance internacional de los mismos. Estos datos y muchos otros de este mismo tenor recogidos en el Libro Blanco de la Oncología en España llevaron a sus autores a concluir que «no se contempla seriamente la investigación oncológica como programa de reconocimiento oficial ni en la Administración Central ni en ninguna de las 17 Comunidades Autónomas españolas».

\section{Evolución reciente de la investigación oncológica en España}

Afortunadamente, a finales de los años 80 y principios de los 90 , la situación de la investigación oncológica comenzó a cambiar apreciablemente. Son varios los factores que a mi juicio contribuyeron al inicio de esta nueva etapa. En primer lugar, podemos mencionar la 


\section{La investigación oncológica en España}

influencia que ejerció la introducción del Plan Nacional de I+D en 1988 , en el que se contemplaba un apoyo explícito a la investigación oncológica. Este hecho animó sin duda a diversos grupos sin una trayectoria previa en este campo, a plantear proyectos de investigación sobre el cáncer. A mi juicio, los responsables de este Plan actuaron generosamente y con notable visión de futuro, y proporcionaron el sustrato suficiente para que varios grupos se incorporaran por primera vez a la investigación oncológica. Fruto de esta apuesta continuada, la financiación fue aumentando paulatinamente hasta alcanzar cifras cercanas a los 500 millones de pesetas anuales que se dedican en la actualidad a proyectos de investigación sobre el cáncer. Cifras similares se destinan actualmente en el FIS para proyectos oncológicos, siendo especialmente reseñable el intento de cambio hacia la financiación de proyectos de mayor cuantía y entidad que los avalados en tiempos anteriores. Un hecho que vino a complementar esta situación cambiante derivó de la reincorporación a España en esos años de un número significativo de científicos que se habían introducido en la investigación oncológica en el extranjero. Varios de estos jóvenes investigadores se habían formado en grupos liderados por destacados científicos españoles como Mariano Barbacid, Joan Massagué, Angel Pellicer, Manuel Perucho o Eugenio Santos, que estaban desarrollando trabajos oncológicos de vanguardia en distintos centros de investigación norteamericanos. En estos mismos años, tuvo lugar un hecho adicional que favoreció un impulso general de la investigación oncológica en nuestro país: la consolidación y expansión de sociedades de investigación oncológica y especialmente la Asociación Española de Investigación sobre el Cáncer (ASEICA) ${ }^{4}$. Esta Sociedad que en la actualidad agrupa a más de 600 investigadores básicos o clínicos, aglutinó una parte significativa de los esfuerzos iniciales en este sentido y destacó en la organización de cursos que en su momento fueron decisivos para trasladar una metodología de investigación oncológica a Centros alejados de Madrid o Barcelona, en donde tradicionalmente se habían concentrado dichas actividades.

A medida que fue transcurriendo la década de los 90, la investigación oncológica española recorrió un camino paralelo al de la práctica totalidad de la Ciencia española en el mismo periodo. Tras los mencionados estímulos positivos se fue entrando lentamente en una etapa en la que la inversión inicial no se concretó en acciones más amplias, la incorporación de jóvenes investigadores con capacidad de iniciar su actividad como científicos independientes fue mucho más limitada de lo necesario, y en definitiva, la mayoría de los grupos encontraron 
grandes dificultades para dotar a su trabajo en investigación oncológica de la dimensión adicional que la magnitud del problema y la competitividad internacional requerían. Algunas iniciativas aisladas, pero sin duda relevantes por insólitas en el panorama científico español, contribuyeron a paliar alguna de estas deficiencias. Tal vez la primera de ellas fue la creación del Departamento de Inmunología y Oncología en el Centro Nacional de Biotecnología (CNB), a través de un acuerdo entre el CSIC y la empresa Pharmacia. Dicho Departamento, dirigido por Carlos Martínez, acogió a jóvenes investigadores como María A. Blasco o Manuel Serrano, que dinamizaron la investigación oncológica con proyectos de gran impacto dentro de nuestra especialidad. Otras compañías multinacionales como Bristol-Myers o Glaxo-Wellcome, apoyaron puntualmente iniciativas de investigadores españoles dentro de la Oncología. Por otra parte, cabe señalar que algunas Fundaciones contemplaron y siguen contemplando específicamente la ayuda a la investigación oncológica como la Fundación Científica de la Asociación Española contra el Cáncer o la Fundación para la Investigación y la Formación en Oncología, mientras que otras han avalado numerosos proyectos de esta temática, siendo éste el caso por ejemplo de la Fundación Ramón Areces. Son los claros y escasos casos de mecenazgo científico tan frecuentes en otros países y tan raros en el nuestro, y que en el terreno concreto de la investigación oncológica deberían estar llamados a desempeñar un papel mucho más relevante del que en la actualidad juegan. Finalmente, debemos resaltar la labor de empresas farmacéuticas españolas que se han incorporado a la investigación oncológica con nuevas ideas y aproximaciones, que tal vez podían abrir caminos de esperanza hacia el futuro no sólo en lo clínico o en lo científico, sino también en los ámbitos técnológicos y económicos. La más representativa de todas ellas puede ser la situación de Pharma Mar, una de las pocas compañías netamente españolas implicada en ensayos multicéntricos internacionales con productos propios. Uno de ellos, denominado ET-743 y extraido de un organismo tunicado del Mar Caribe, ha atravesado con éxito las primeras fases de ensayo clínico y puede ser de futura utilidad para el tratamiento de distintos tipos de tumores, especialmente sarcomas.

En cualquier caso, y más allá de todas estas iniciativas que surgen esencialmente de acciones individuales o puntuales, recientemente hemos asistido a la presentación de un ambicioso proyecto en el marco de la investigación sobre el cáncer en nuestro país: la creación del Centro Nacional de Investigaciones Oncológicas Carlos III (CNIO) ${ }^{5}$. Este Centro, dirigido por Mariano Barbacid, estará ubicado en el antiguo 
Hospital Victoria Eugenia de Madrid una vez concluyan las obras de remodelación presupuestadas en 4.500 millones de pesetas y sufragadas en su totalidad por el Ministerio de Sanidad y Consumo. Se espera que el CNIO abra sus puertas a finales del año 2001, aunque las actividades científicas de alguno de sus Programas como el de Oncología Molecular han comenzado ya en laboratorios cedidos por el CSIC en el CNB. Además, se han iniciado algunas acciones que tratan de ir más allá de la investigación básica proponiendo vías de aplicación clínica como la creación de un Banco de Tumores y el desarrollo de chips genéticos que permitan la puesta en marcha de un programa de diagnóstico molecular del cáncer en los Hospitales españoles.

\section{El futuro de la investigación oncológica en España}

El cáncer es un problema universal a cuya resolución o alivio todos debemos contribuir y España no puede quedar al margen. Parece obvio, por tanto, que la apuesta por la investigación oncológica a todos los niveles debería ser una prioridad absoluta en nuestro país. En los últimos años hemos asistido a una impresionante serie de hallazgos moleculares y mecanísticos que han facilitado la comprensión de muchas facetas de los procesos de carcinogénesis, la mejora de los procedimientos de diagnóstico de la enfernedad y la introducción de nuevas terapias ${ }^{6}$. Como consecuencia de estos hechos, han aumentado las expectativas de curación de aquellos tumores para los que hoy no tenemos soluciones satisfactorias. El gran reto planteado, aquí y en cualquier otro lugar del mundo, es proseguir con los avances en la investigación básica y trasladarlos a la clínica lo antes posible. Al mismo tiempo, es imprescidible que se arbitren estrategias y procedimientos que conduzcan a una prevención del cáncer mucho más eficaz, aspecto que sigue estando notablemente desatendido en nuestro país.

Resumiendo la situación actual de la investigación oncológica española, podemos señalar que tras un pasado precario, se abre un futuro expectante. Durante años, la investigación oncológica se ha realizado de forma aislada, sin una programación definida, ni un apoyo específico por parte de las diversas instituciones. Por ello, deberá consolidarse la iniciativa del CNIO y demostrar que por primera vez hay una clara política científica estatal en el terreno de la investigación oncológica. Asimismo, iniciativas como la creación del Instituto de Investigación del Cáncer en Salamanca, u otras similares surgidas en distintos puntos de la geografía española, deberán recibir el apoyo preciso para facilitar 
su desarrollo. En el terreno de la investigación clínica debería aprovecharse científicamente la reciente puesta en funcionamiento de centros oncológicos en Barcelona y Madrid, dependientes de centros americanos de gran prestigio como el Memorial Sloan Kettering Cancer Center o el MD Anderson Cancer Center. El futuro también anuncia la incorporación de científicos españoles con trayectorias excelentes en el extranjero y de cuya experiencia podemos extraer grandes lecciones. En cualquier caso sería imprescindible que junto a ellos ocupen su lugar sin la acostumbrada precariedad en formas y fondos, aquellos jóvenes científicos con las dosis de ambición e ilusión suficientes para intentar contribuir con nuevo impulso al conocimiento y tratamiento de las enfermedades neoplásicas.

Para concluir, me gustaría señalar que este artículo no ha pretendido bajo ninguna circunstancia ser exhaustivo, sino sólo una breve reflexión acerca de diversos aspectos de la investigación oncológica española. Pido disculpas anticipadas por las involuntarias omisiones de los nombres de aquellos que han colaborado en una u otra manera al desarrollo de la investigación oncológica en nuestro país, y que aquí no han quedado reflejados explícitamente. Para una lectura curiosa de alguno de los avatares que sufrió nuestra disciplina a lo largo de su corta historia, remitiría a los lectores a un reciente artículo sobre los orígenes de la Oncología en España, en el que se hace especial énfasis en los aspectos de investigación clínica ${ }^{7}$. En cualquier caso, parece evidente que en el desarrollo de esta disciplina en nuestro país tal vez se eche de menos el liderazgo que científicos como Eladio Viñuela, a quien se dedica este número de la revista Arbor, ejercieron en otros ámbitos como la Biología Molecular o la Virología. A medida que pasa el tiempo desde que Eladio se despidió de la vida, su influencia en muchos de nosotros se percibe cada vez con mayor nitidez. Esperemos que en la futura historia de la investigación oncológica en España, surjan nombres como el suyo, con la capacidad de impulsar definitivamente una disciplina que trata de buscar soluciones a un problema apasionante desde una perspectiva científica y tantas veces dramático desde un punto de vista humano y social.

\section{Notas}

1. Valladares Y, Alvarez Y. La investigación oncológica. Libro Blanco de la Oncología en España, $2^{a}$ edición, pp 219-246, FESEO-Madrid, 1994. 


\section{La investigación oncológica en España}

2. Fernández E., Borrás JM, Levi F, Schiaffino A, García M, LaVecchia C. Med Clin 114:449-451, 2000.

3. Valladares, Y. Memoria y Actas del Primer Congreso de Investigación sobre el Cáncer en España (Valladares Y, editor) Madrid, 1983.

4. Asociación Española de Investigación sobre el Cáncer (ASEICA) www.onco.net/ aseica.

5. Centro Nacional de Investigaciones Oncológicas (CNIO) www.cnio.es.

6. Muñoz, A. Cáncer: genes y nuevas terapias. Editorial Hélice, Madrid, 1997.

7. Vicente, J. Apuntes para una historia de la Oncología en España. Oncología 23:310-317, 2000. 